\title{
Belt conveyers rollers average term of service
}

\author{
Andrii Smirnov $^{1, *}$, and Vsevolod Beihul ${ }^{2}$ \\ ${ }^{1}$ Institute of Geotechnical Mechanics named by N. Poljakov of National Academy of Sciences of \\ Ukraine, 49005, Dnipro, Simferopolska Str., 2a, Ukraine \\ ${ }^{2}$ Dniprovsk State Technical University, 51918, Kamianske, Dniprobudivska Str., 2, Ukraine
}

\begin{abstract}
The paper is proved to one of the important conveyer transport system task - to roller's term of service (TS) determination. The task solving permit to evaluate the different designs belt conveyers reliable. The article represent the tasks of belt conveyers roller's average TS determination were set and solved for the different types of roller supports. Dynamic efforts arised with the loading motion and caused with belt bend are principal factor for the calculation of TS rollers. The graph of dependence roller's average TS from belt velocity for different roller's types were obtained. Obtain analyses results permit to set: average roller TS decrease under velocity increases for all types of roller's, TS for dumping overhead roller supports and damping roller supports is substantially greater, then for hard and overhead roller supports. In addition, at some values of the belt velocity TS service can sharply decrease for all types of roller supports. It takes place in resonances related to vibrations of belt at motion of large pieces of load. Achieved results may be applied in mining, metallurgical and building industry.
\end{abstract}

\section{Introduction}

Conveyor framework with roller support is an important part of a belt conveyor, the technical condition of which determines the reliability of the conveyor as a whole.

Reliability of the framework is determined by the reliability of the rollers of the roller supports, as the reliability of the supporting metal structures is much higher.

An important indicator for assessing the reliability of a roller is its term of service, depending on the type, parameters of roller supports and operating conditions.

The task of determining the term of service of belt conveyor rollers was studied by L.H. Shakhmeister, V.H. Dmitriev, V.F. Monastyrsky, A.I. Dodatko and other researchers. Their works showed that the main cause of roller failure is the failure of the bearing unit, the loads on the rollers during transportation of the rock mass are determined and, on the basis of this, formulas for calculating their term of service are proposed. When this load on the bearings of the rollers, arising from large pieces of load, not considered accurately enough.

In $[1,2]$, formulas are proposed for calculating the average term of service of belt conveyor roller bearings. However, when describing the load on the roller bearing, the

\footnotetext{
*Corresponding author: sm.contur24@gmail.com
} 
authors did not take into account the dynamic forces arising from the movement of the load on the conveyor belt and due to the bending of the belt.

Analysis of the failures of the belt conveyor framework showed that the main reasons for the failure of the rollers are increased radial clearance in the bearing due to abrasive wear and fatigue failure of bearing elements from the effects of dynamic loads [3]. Therefore, the term of service of one roller is determined by the term of service of the bearings.

The purpose of this work is to determine the term of service of belt conveyor rollers for various types of roller supports.

\section{Methods}

The durability or $90 \%$ service life of rolling bearings $L_{09}$, measured in hours, is determined according to [3]:

$$
L_{09}=\left(\frac{C_{n}}{P_{m}}\right)^{p} \cdot \frac{10^{6}}{60 n} k_{o},
$$

where $C_{n}$ is the dynamic load capacity, $\mathrm{N}$, (the load at which the durability is 1 million revolutions, this value for each particular bearing is selected from the directory); $P_{m}$ is the equivalent dynamic load on the roller bearing, $\mathrm{N} ; n$ is the bearing rotation frequency, $1 / \mathrm{s}$; $p$ is the power index ( $p=3$ for ball bearings and $p=10 / 3$ for roller bearings); and $k_{\mathrm{o}}$ is the coefficient taking into account the operating conditions.

The average term of service of the bearing, according to [4], is determined from the ratio

$$
t_{a}=4.08 \cdot L_{09}
$$

The frequency of rotation $\mathrm{n}$ is determined by the formula:

$$
n=\frac{60 v_{b}}{2 \pi r}
$$

where $v_{b}$ is the speed of the conveyor belt, $\mathrm{m} / \mathrm{s} ; r$ is roller radius, $\mathrm{m}$.

In our case, the roller bearing unit is loaded with a load flow, with a radial and axial load on the bearing. The axial load on the bearing is neglected, because the impact of the load on the bearing is transmitted through the metal cup and the share of the axial component is small. Therefore, radial and radial thrust bearings are used in the rollers of the considered conveyors. For ball radial and radial thrust bearings, as well as roller radial thrust bearings, the dynamic radial load is calculated using the formula [5]:

$$
P_{m}=V K_{t} K_{s} F_{r}
$$

where $F_{r}$ is the radial load on the bearing; $V$ is the coefficient of rotation (when the outer ring of the bearing rotates with respect to the load $V=1.2$ ); $K_{t}$ is the temperature coefficient chosen from the tables [5] (in our case $K_{t}=1$ ); and $K_{s}$ is the safety factor chosen from the tables [5] (in our case, we assume $K_{s}=1$, since the influence of the nature of the load on the bearing is taken into account when calculating $F_{r}$ ).

On this basis, the total dynamic radial load on the roller bearing is:

$$
P_{m}=1.2 F_{r}
$$


The radial load on the bearing $F_{r}$ can be represented as the average load on the bearing:

$$
F_{r}=\frac{1}{2} M[x(t)]
$$

where $M[x(t)]$ is the mathematical expectation of the load on the central roller of the roller support; and $x(t)$ is a random function of the load on the roller support.

In [6], a statistical model of the load flow is presented, which is considered as a small fraction and large pieces located in it.

According to this work, $M[x(t)]$ is determined by the formula

$$
M[x(t)]=0.5 \sum_{i}^{s} g k_{d i} \tau_{l} Q P_{i}+q_{l} l_{r},
$$

where $P_{i}$ is the weight fractions of pieces of the $i$-th fraction in the total weight of the load delivered to the conveyor; $Q$ is the conveyor capacity, $\mathrm{kg} / \mathrm{s} ; k_{d i}$ is the coefficient of dynamism in the interaction of a piece of load $i$-th fraction with roller; $l_{r}$ is the distance between rollers (pitch rollers), $\mathrm{m} ; \tau_{l}$ is the time of interaction of a large piece of load with roller, $\mathrm{s} ; q_{l}$ is the linear load on the bearing unit, $\mathrm{N} / \mathrm{m} ; g$ is the gravitational acceleration, $\mathrm{m} / \mathrm{s}^{2}$; and $s$ is the number of fractions.

A large piece interacts with the roller for two spans between the rollers, therefore, $\tau_{l}$ is defined as

$$
\tau_{l}=\frac{2 l_{r}}{v_{b}} .
$$

Load $q_{l}$ taking into account the uneven load on the side and middle rollers is determined by the formula [7]

$$
q_{l}=0.7 k_{d}^{\prime} \cdot\left(q_{s}+q_{b}\right)+q_{r}
$$

where $q_{s}$ is the linear load on the belt from the small fractions (i.e., with the exception of the percentage of large fractions considered separately), $\mathrm{N} / \mathrm{m} ; q_{b}$ is the linear weight of the belt, $\mathrm{N} / \mathrm{m} ; q_{r}$ is the weight of the rotating parts of the roller, $\mathrm{N}$; and $k_{d}^{\prime}$ is the coefficient of dynamism in the interaction of the small-sized fraction with the roller support.

In formula (8), the coefficient 0.7 takes into account the part of the load perceived by my middle roller.

The dynamic factor $k_{d}^{\prime}$ accordant [8] is determined on a formula

$$
k_{d}^{\prime}=1+\frac{v_{b}^{2}}{g} \cdot \frac{q}{\left(S_{b}-q v_{b}^{2} / g\right)},
$$

where $q=q_{s}+q_{b}$; and $S_{b}$ is tension of the belt, N.

The conveyor capacity $Q$, according to [1], is determined by the formula

$$
Q=\frac{q_{f} v_{b}}{g}
$$

where $q_{f}$ is the unit weight of load, including small and large fractions, $\mathrm{N} / \mathrm{m}$.

When determining the load on the roller, pieces of those fractions are taken into account, for which the average distance between the pieces $l_{i}$ is greater than the distance 
between the roller supports $l_{r}\left(l_{i}>l_{r}\right)$, that is, it is assumed that at the moment only one large piece interacts with the roller support.

From the formula (6) it can be seen that the average load on the roller of the roller supports depends on the dynamic factor $k_{d i}$ when interacting with a piece of each fraction and the composition of the transported load. As studies have shown [8], $k_{d i}$ depends on the design of the roller and the parameters of the conveyor.

\section{Result and discussion}

Substituting (4) into (1), taking into account (5) - (9), and then substituting the resulting expression for the resource $L_{09}$ into (2), we finally determine the average term of service of the bearing.

The analysis showed that the term of service of the conveyor rollers depends on the linear load, the parameters of the conveyor, the composition of the transported load and the type and parameters of the roller conveyor.

Figures 1 and 2 show the dependences of the roller $t_{a}$ average term of service on the belt speed $v_{b}$ for two types of rollers: on a hard framework (hard rollers) (Fig. 1) and overhead on a cable framework (overhead roller supports) (Fig. 2). For comparison, the selected rollers with a diameter of $133 \mathrm{~mm}(r=0.0665 \mathrm{~m})$, used in type $1 \mathrm{~L} 100 \mathrm{~K}$ conveyors. In these rollers bearings \#304 are used. In this case, the conveyor parameters were taken as follows: belt tension $S_{b}=20000 \mathrm{~N}$, linear weight of load $q_{f}=1500 \mathrm{~N} / \mathrm{m}$, roller pitch $l_{r}=1 \mathrm{~m}$, cable tension $S_{c}=30000 \mathrm{~N}$.

The dynamic load capacity $C_{n}$ for bearing \#304 was selected from tables [5]. For this bearing, $C_{n}=5500 \mathrm{~N}$. The weight fractions of pieces of the $i$-th fraction $P_{i}$ were taken from table 1 [6]. Also from this table, the values of the average distance between the middle of the pieces of the $i$-th fraction li were chosen.

Figures 1 and 2 show that with an increase in the speed of the conveyor belt for hard and overhead roller supports, the average term of service of the rollers decreases. The value of the average term of service of the rollers in the range of change of the speed of the conveyor $0<v_{b}<3 \mathrm{~m} / \mathrm{s}$ for hard roller supports is slightly higher than the term of service of rollers for overhead rollers.

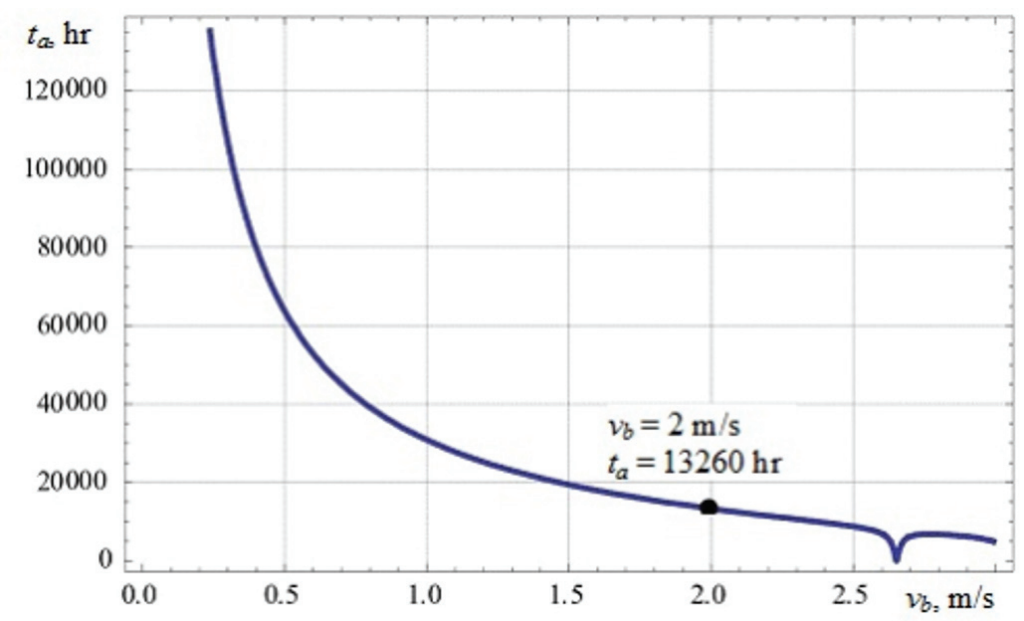

Fig. 1. Graph of the average term of service of the roller on conveyor belt speed for hard roller supports. 


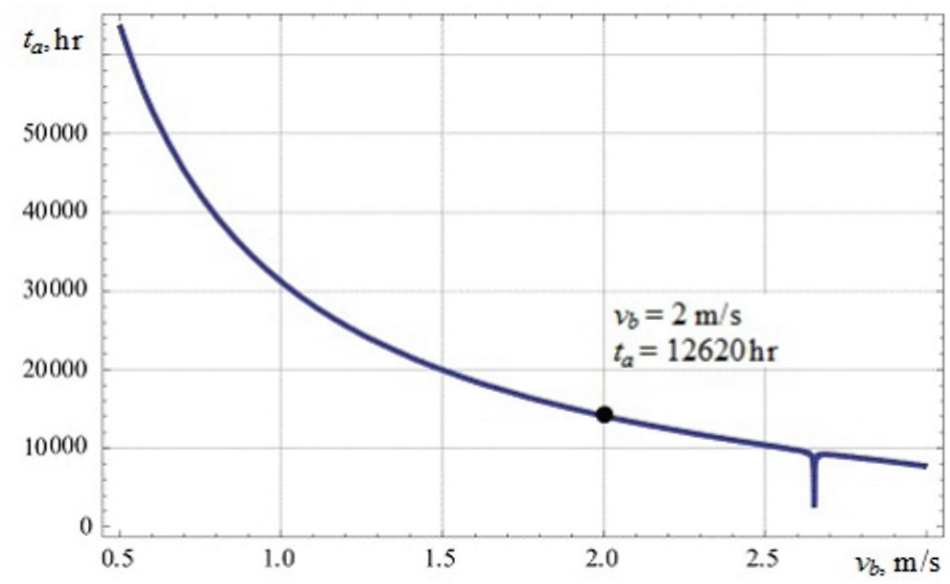

Fig. 2. Graph of the average term of service of the roller from the speed of the conveyor belt for overhead roller supports on a cable framework.

In addition, from Figures 1 and 2, it can be seen that for hard and overhead roller supports, as the belt speed approaches the value of $2.65 \mathrm{~m} / \mathrm{s}$, the average roller resource decreases sharply. This is due to the fact that for these rollers, when moving pieces of load of the largest fraction together with the conveyor belt with this speed, a resonance of the belt causes a resonance at which the dynamic force on the roller rises sharply.

Figures 3 and 4 show the dependences of the average term of service of the roller on the belt speed for the damping (Fig. 3) and damping overhead (Fig. 4) roller-supports with the same conveyor parameters as for the previous types of roller-bearings. The stiffness of the shock absorbers took the value of $c=20000 \mathrm{~N} / \mathrm{m}^{2}$. From these figures it is seen that, as in the previous case, with increasing belt speed, the roller's term of service decreases. At the same time, the term of service for the damping roller supports is more than for damping overhead by $3 \%$. In addition, these figures show that for certain values of belt speeds $\left(v_{b}>2 \mathrm{~m} / \mathrm{s}\right)$, the service life of the rollers sharply decreases. It is also associated with the phenomenon of resonances as a result of oscillations of the belt when moving pieces of load of large fractions.

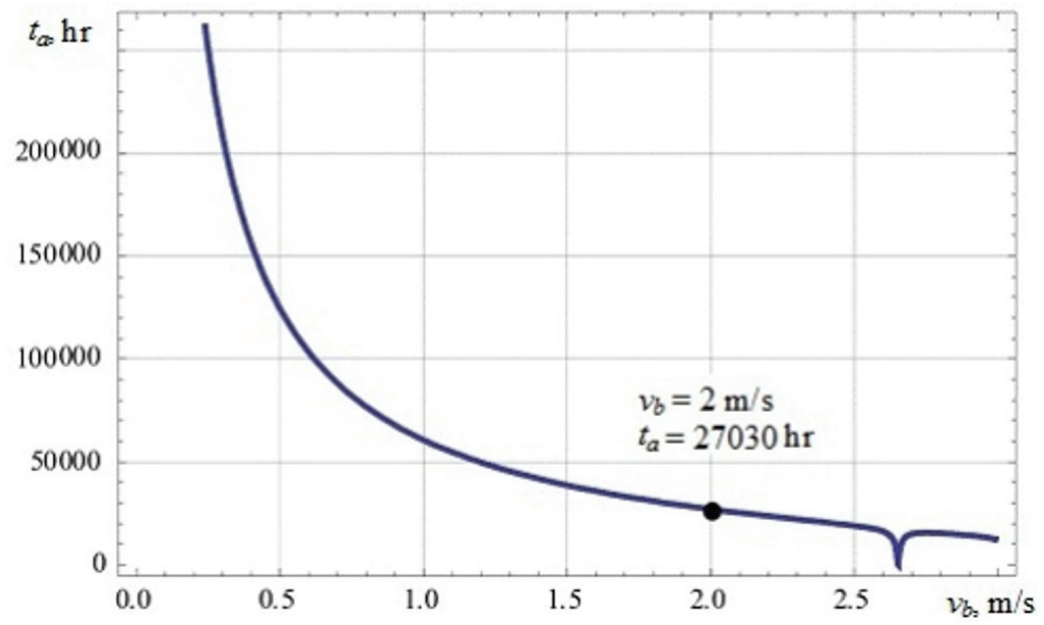

Fig. 3. Graph of the average term of service of the roller from conveyor belt speed for damping roller supports. 


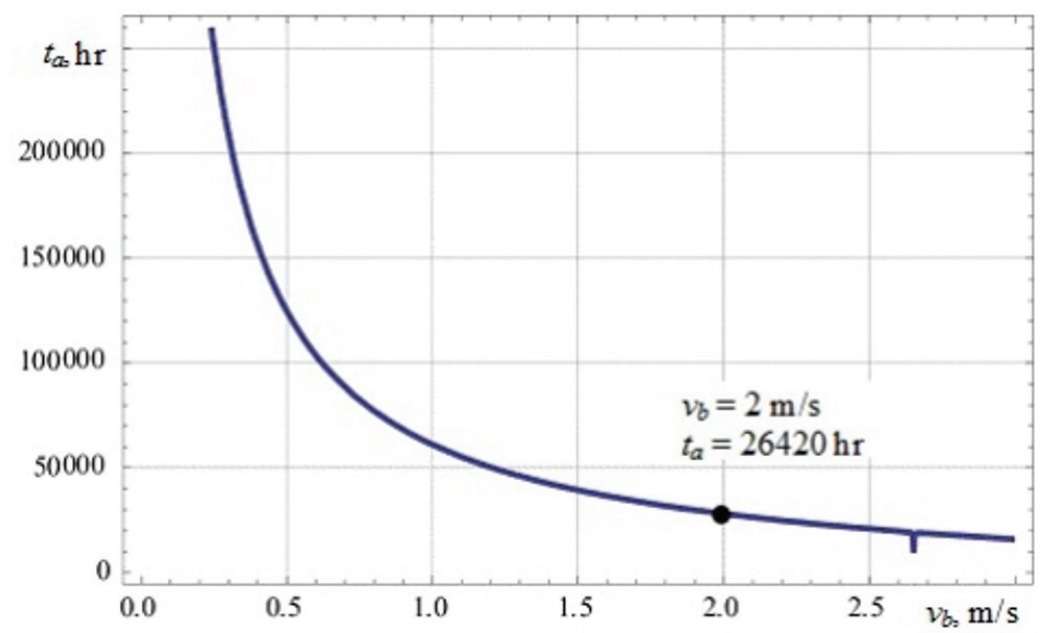

Fig. 4. Graph of the average term of service of the roller on the conveyor belt speed for overhead roller supports on a cable framework with damping suspensions (for overhead damping roller supports).

\section{Conclusions}

The service life of the conveyor rollers depends on the linear load, the parameters of the conveyor, the composition of the transported load and the type and parameters of the roller support. At the same time, with an increase in the speed of the conveyor belt for the considered types of rollers, the average term of service of the rollers decreases. When the belt speed changes to certain values, the service life of the rollers for hard roller supports is somewhat higher than for overheard roller supports, and the term of service of rollers for damping roller supports is somewhat higher than for damping overhead roller supports.

At the same time, the term of service for damping overhead and damping roller supports is significantly higher than for hard and overhead. In addition, when the belt speeds are higher than some values for all considered types of roller supports, the roller's term of service can sharply decrease due to the appearance of resonant phenomena associated with belt vibrations during the movement of pieces of large fractions.

\section{References}

1. Galkin, V.I., Dmitriev, V.G., Dyachenko, V.P. (2005). Sovremennaya teoriya lentochnykh konveyerov gornykh predpriyatiy. Moskva: MSMU

2. Seyed, A.Sh. (2009). Roller supports of powerful belt conveyers linear sections rational parameters substantiation for mining enterprises, $\mathrm{Ph}$. D. Thesis, Mining Machines, Moscow

3. Shakhmeyster, L.G., Dmitriev, V.G. (1983). Veroyatnostnye metody pascheta transportiruyushchikh mashin. Moskva: Mashinosrtoenie

4. Sprishevskiy, A. I. (1969). Podshipniki kacheniya. Moskva: Mashinosrtoenie

5. Chermenskiy, O.N., Fedotov, N.N. (2003). Podshipniki kacheniya. Spravochnikkatalog. Moskva: Mashinosrtoenie

6. Monastyrskyi, V.F., Kiriya, R.V. Smirnov, A.N. (2011). Bulk freight and roller supports interaction statistic model for belt conveyers. Geo-Technical Mechanics, 93, 87-93

7. Zenkov, R.P., Ivashkov, I.N., Kolobov, P.I. (1987). Mashiny nepreryvnogo transporta. Moskva: Mashinosrtoenie 
8. Monastyrsky, V.F., Kiriya, R.V., Smirnov, A.N. (2013). Large fraction bulk material motion on a belt conveyer roller supports investigation. Geo-Technical Mechanics, 112, 35-47 